\title{
Effect of duration of sonication during gelatinization on properties of tapioca starch water hyacinth fiber biocomposite
}

\begin{abstract}
This paper characterizes properties of biocomposite sonicated during gelatinization. The biocomposite consisted of tapioca starch based plastic reinforced by $10 \%$ volume fraction of water hyacinth fiber (WHF). During gelatinization, the biocomposite was poured into a rectangular glass mold then vibrated in an ultrasonic bath using $40 \mathrm{kHz}, 250 \mathrm{~W}$ for varying durations $(0,15,30$, and $60 \mathrm{~min})$. The resulting biocomposite was then dried in a drying oven at $50{ }^{\circ} \mathrm{C}$ for $20 \mathrm{~h}$. The results of this study indicate that a biocomposite with optimal properties can be produced using tapioca starch and WHF if the gelatinizing mixture is exposed to ultrasound vibration for $30 \mathrm{~min}$. After this vibration duration, tensile strength (TS) and tensile modulus (TM) increased $83 \%$ and $108 \%$. A further $60 \mathrm{~min}$ vibration only increased the TS at $13 \%$ and $\mathrm{TM}$ at $23 \%$. Moisture resistance of the biocomposite after vibration increased by around $25 \%$ reaching a maximal level after $30 \mathrm{~min}$. Thermal resistance of the vibrated biocomposites was also increased.
\end{abstract}

Keyword: WHF-tapioca starch biocomposite; Mechanical and thermal properties; Moisture absorption; Vibration duration 